\title{
ENTRAVES SÓCIO-ECONÔMICOS:EXCLUSÃO DIGITAL, UMA QUESTÃO DE CONSCIENTIZAÇÃO E AÇÃO
}

\author{
Sthênio Diego do Nascimento Pessoa
}

Aluno do curso de Licenciatura em Física do CEFET-RN. stheniopessoa@yahoo.com.br

\section{RESUMO}

A existência do fenômeno social da exclusão digital, bem como, suas conseqüências negativas, não apenas ao indivíduo mas à sociedade como um todo, é um fato. A partir deste, este artigo visa conscientizar a população dos avanços exponenciais das tecnologias da informação, suas melhorias ao processo ensino-aprendizagem e, principalmente da necessidade de uma inclusão digital da massa como forma de dar-lhes garantias de (re) integração ao mercado de trabalho / (re) integração do saber. Dividimos o artigo em quatro partes. Na primeira apresentaremos a questão. Na segunda, abordamos o favorecimento estabelecido aos incluídos digitais, através de exemplificações . Na terceira, apresentamos dois programas de inclusão digital em fase de implantação no município de Natal e outro a nível estadual (RN) (julho/2004). E, por último propomos um plano (iniciativas) que levam à uma ação, no sentido de minimizar ou, idealmente extinguir tal fenômeno info-social.

Palavras-chave: Educação on-line, Internet, Inclusão/Exclusão digital, EaD, invisibilidade social.

\section{FETTER PARTNER-ECONÔMIC:EXCIUSION DIGITAL, A SUBJECT OF UNDERSTANDING AND ACTION}

\begin{abstract}
The existence of the social phenomenon of the digital exclusion, as well as, your negative consequences, not just to the individual but also to the society as a whole, is a fact. Starting from this, this article seeks to become aware the population of the exponential progresses of the technologies of the information, your improvements to the process teaching-learning and, mainly of the need of a digital inclusion of the mass as form of giving them guaranteed of (re) integration to the job market / (re) integration of the knowledge. We divided the article in four parts. In the first we will present the subject. On second, we approached the established to favor to the included digital, through examples. In the third, we presented two programs of digital inclusion in implantation phase in the municipal district of Natal and other at state level (RN) (julho/2004). And, last we propose a plan (initiatives) that take to an action, in the sense of minimizing or, ideally to extinguish such an info-social phenomenon.
\end{abstract}

Keywords: On-Line education, Internet, Digital exclusion/inclusion, Distance Learning, Social invisibility. 


\section{ENTRAVES SÓCIO-ECONÔMICOS: EXCLUSÃO DIGITAL, UMA QUESTÃO DE CONSCIENTIZAÇÃO E AÇÃO}

\section{INTRODUÇÃO}

A dependência do indivíduo à sociedade é um fato. Tal fato demonstra a necessidade de indivíduos estarem inseridos em todo um contexto social, no qual podemos citar o fenômeno info-social da inclusão/exclusão digital. Abordaremos neste artigo a fatídica existência de indivíduos à margem das novas tecnologias da informação, do acesso à Internet - os chamados excluídos digitais - bem como, proporemos modelos solucionadores para esta questão.

O homem sempre necessitará de aprimoramento por parte das tecnologias, necessitando sempre de um processamento mais eficiente por parte destas tecnologias da informação (não só dos computadores em si), de uma máquina mais veloz, mais ágil, daí ele ser chave também do processo de a tecnologia caminhar a largos passos, pois o ser humano tem a aptidão da criatividade como ponto chave de sua motivação, e o desejo de romper barreiras, "O ser humano é a única máquina dotada de inteligência, esta como sendo a capacidade de aprender a aprender, justamente por estes interesses em superar-se, adquirir novos conhecimentos, aprimorar-se.” (Minsky, 1995).

De fato, a realidade é extremamente dinâmica e, existem pessoas que ainda não têm se quer acesso às tecnologias da informação, na chamada era digital, onde equipamentos diversos integram-se, onde é possível que máquinas assumam o controle de outras máquinas automatizando processos.

Um fato ressaltante, tanto no processo de automação industrial, por exemplo, quanto de qualquer outro sistema onde as tecnologias da informação estejam presentes, há um fator de proteção intelectual - um regime de patentes - que, muitas vezes encuba o conhecimento, além do pagamento de taxações a título de propriedade intelectual que elevam o preço final da tecnologia, constituindo na verdade um fator ao acesso a camadas menos favorecidas economicamente. Isto gera, restringindo a tecnologias da informação, uma parcela da população marginalizada (no sentido de estar à margem, excluída) do processo de evolução digital ou "excluídos digitais". essa seria a parcela da população que não teria acesso a esta tecnologia por não disporem de um capital necessário para conhecela.

Tal fato constitui a deflagração de uma grave crise social-capitalista eminente, ora, se o indivíduo não tem acesso às novas tecnologias da informação, pois não tem renda familiar para freqüentar instituições de ensino de qualidade onde exista uma política de incentivo ao uso dessas tecnologias onde haja, de fato, um processo de ensino-aprendizagem enfocando novas tecnologias, este "objeto” doravante denominado excluído digital, já se encontra, ultrapassado frente ao padrão tecnológico vigente - isto leva a um efeito bastante conhecido por economistas denominado efeito dominó - ou seja, se esse indivíduo já está ultrapassado frente ao padrão tecnológico vigente ou nem mesmo tem conhecimento deste, isso acarretará que dificilmente terão acesso a uma fonte de renda proveniente de qualquer área do conhecimento científico que lhes permita ascender economicamente.(FUNDAÇÃO GETÚLIO VARGAS -CENTRO DE POLÍTICAS 
SOCIAIS. Mapa da exclusão digital:Sumário executivo. Disponível em <http://www2.fgv.br/ibre/cps/mapa_exclusao/SUMARIO/sumario\%20interativo.htm>)

\section{SEGUNDA PARTE}

Indivíduos que têm acesso à tecnologias de última geração o quanto antes, são os maiores exemplos de pessoas que obtiveram sucesso por isso. Como exemplo de fácil percepção, podemos citar o milionário Bill Gates, proprietário da gigante americana Mycrosoft ${ }^{\circledR}$; Gates não foi o exemplo clássico da pessoa que não tinha nada e, de repente tudo veio a ele, ele foi hábil e teve visão empreendedora ao fundar a Microsoft ${ }^{\circledR}$ de fundo de quintal, e mais fez isso na hora certa !. Gates é uma pessoa inteligente tem autoridade pelo conhecimento mas não coloco aí o grande peso de sua visão empreendedora, ele teve oportunidade de conhecer de perto ferramentas tecnológicas "de ponta” o que com certeza lhe abriu os olhos do entendimento. O sucesso é alicerçado num tripé composto por visão de mercado, ação (empreendedora) e oportunidade. "Se pude ver mais longe que os outros, foi por estar apoiado sobre ombro de gigantes" (Newton,1824-1887). Um outro fator interessante é que Gates não se limitou e, ainda não se limita a implementar apenas suas próprias idéias : "Existem mais pessoas com excelentes idéias do que capazes de executálas” (Gates, 1982), embora tenha dito paradigmaticamente "640Kb são suficientes para qualquer um” (Gates, 1982), Gates aprendeu com isso, paradigmas apresentam esta característica, jamais diga a alguém que isto ou aquilo é limitado no universo da tecnologia da informação, em fim no meio científico.Se tivesse se limitado a implantar apenas suas idéias Gates teria parado no Visual Basic ${ }^{\circledR}$, ele foi hábil em implantar as idéias dos outros e, dizem as más línguas que até copiou algumas...

Atualmente as tecnologias da informação revolucionam o mercado e a educação está cada vez mais facilitada. O advento da popularização da Internet (a dez anos atrás apenas universidades, governo e forças armadas detinham acesso à rede) tem aberto aos internautas um leque de infinitas possibilidades o qual colocam também professores e alunos em um patamar de igualdade (frente à possibilidade de acesso "irrestrito" à informação e também de publicação de informações próprias) atuantes como compartilhadores mútuos de conhecimento.No entanto, a tecnologia voltada à educação não está restrita a consulta de informações de forma estática parametrizando o site com o professor exemplo da pedagogia tradicional ou a "caixinha do conhecimento" não, a tecnologia revoluciona a partir de que o fluxo pode ocorrer no sentido multidirecional sob uma tecnologia/metodologia denominada "EaD - Educação à Distância” - tendo sua popularização devida à "popularização” da Internet "banda larga”.

No estado do RN, a Internet banda larga teve sua difusão principiada no ano 2000 pela Cabo Tv por Assinatura, empresa de capital binacional (Brasil e Argentina) no Brasil, com capitais do grupo Ecocil que, por sua vez tem seus capitais oriundos da cacinicultura (criação de camarões) quando esta atividade ainda não era tão difunda no estado. Pois bem, o fato é que, a partir dessa atuação da Internet banda larga houve uma revolução no uso da rede, passando a fazer parte do cotidiano dos internautas atividades como, por exemplo, ouvir web rádios, utilizar ferramentas de comunicação instantânea como o MSN Messenger da Mycrosoft ${ }^{\circledR}$ e viabilizou a propagação de E-cursos, como por exemplo, o curso de linguagem de programação C/C++ (UFMG. Curso de linguagem C. Disponível em <http://www.ead.eee.ufmg.br/cursos/C $>$ ) cursos disponibilizados de maneira on-line (tempo real) no qual alunos e professores podem de forma assíncrona e até síncrona trocar 
orientações e realizarem tais cursos até com exames avaliativos e concedente de certificação válida pelo ministério da educação emitido por estas instituições (principalmente universidades e escolas técnicas). Por este meio podem ser disponibilizados que aulas/exposições e apresentações possam ser ministradas remotamente para um público espalhado por todo o mundo, bem como é possível um retorno também para que possa existir diálogo professor/aluno (vídeo conferência).Observe figura a seguir que sintetiza o uso da Internet em sala de aula.

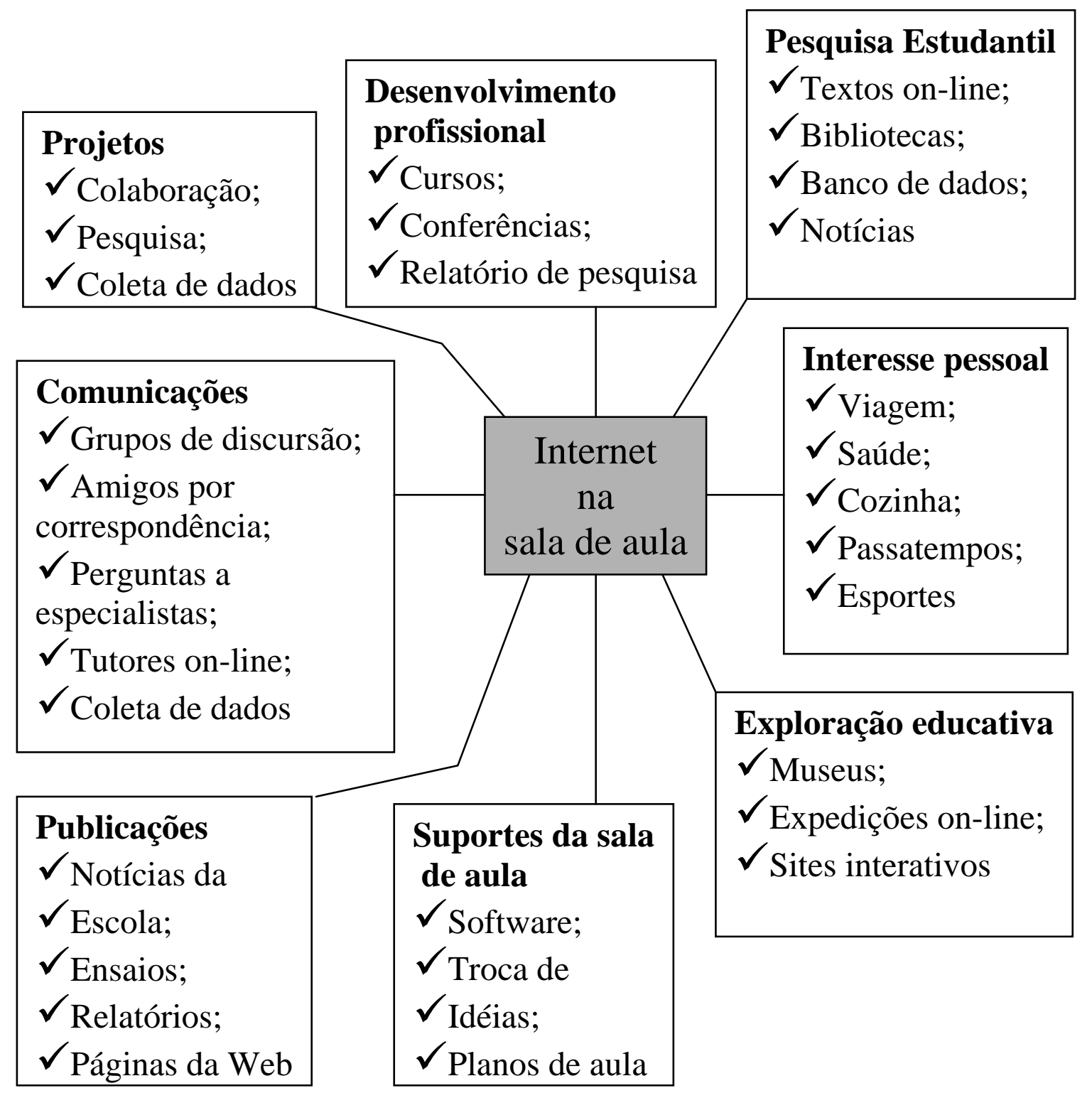

Figura 1 - Internet na sala de aula.

Fonte: Heider (2000, p. 31) citado por Falcão (2001, p. 5) 
A disponibilidade destes recursos tem proferido à parcela incluída digitalmente grandes avanços no mundo em que a informação vale muito, é preciso ser hágil na manipulação de informações, onde "Qualidade total é fazer bem feito na primeira vez”.

\section{TERCEIRA PARTE}

A empresa Telemar S/A, provedora de acesso à Internet e Telefonia fixa atuante no estado do Rio Grande do Norte e em mais alguns estados brasileiros fechou um acordo em junho/2004 com o município de Natal/RN na qual se compromete a dispor gratuitamente a 20 escolas municipais com instalação e manutenção de uma rede de computadores para compor o laboratório de informática dessas escolas incluindo o acesso banda larga à Internet pelo período de 01 ano, a empresa tem uma preocupação social com o fenômeno da exclusão digital e propiciará a centenas de estudantes excluídos digitais (em potencial) um programa de inclusão digital que contará com a capacitação de 20 professores (um por escola) sob a indicação da direção local da escola que ocorrerá na USP - Universidade de são Paulo, uma das mais renomadas instituições de ensino superior no país com todos os custos bancados pela empresa, o projeto de inclusão digital já beneficia 67 escolas em 16 estados brasileiros (CAMPOS, B. T. Escolas municipais terão acesso à Internet: depoimento [4 de julho, 2004]. Natal: Pirangi Notícias. Entrevista concedida a Gladson Morais).

O governo do Estado do RN em parceria com a iniciativa privada assinanou acordos para criação de um Centro de tecnologia da informação, destinando uma verba de quase 2 milhões de reais a este projeto que gerará emprego, renda, além de pessoal qualificado, o centro será uma referência Nacional. (FARIAS, W. M. Centro tecnológico da Informação: depoimento [13 de julho, 2004]. Natal: RNE. Depoimento concedido em cadeia de rádio local).

Iniciativas como essas são exemplo a ser seguido por outras empresas - visto ser de nosso conhecimento a existência de incentivos financeiros por parte dos governos a empresas que invistam no social, deduzindo estas em suas declarações de imposto de renda, a sociedade ganha com isso, pois, de uma vez que a iniciativa privada passa a atuar diretamente na fiscalização de seus recursos investidos ela acaba por garantir que este de fato venha a ocorrer, e ainda projetos como esses diversifica os recursos a áreas que podem estar fora dos interesses políticos do governo, que, não sendo por esses projetos da iniciativa privada estariam “encostados”.

\section{CONCLUSÕES}

Tanto o "invisível social”, como o “excluído digital” são parcelas integrantes de nossa sociedade e, embora estejam à margem de um convívio sócio-econômico, trata-se de cidadãos e concidadãos deste país e, como tal têm direito à moradia, segurança, saúde e educação de qualidade e respeito. Infelizmente, o governo não dispõe de uma infraestrutura para oferecer um serviço "gratuito" de qualidade (observe tabela 01), o que corresponderia em um investimento (a longo prazo), visto que, sabendo que o conhecimento é a chave para um desenvolvimento sustentável, este é, também a chave para a eliminação dos bolsões de miséria (re)integrando este indivíduo à sociedade à medida que passasse a existir uma mobilidade social (ascenção por meios destes, agora justa e igualitária pelo poder conferido por conhecimento ), é preciso desenvolver/atenuar as iniciativas existentes com ações sociais oriundas de organizações governamentais - 
principalmente, porém, também admite-se ação de organizações não-governamentais, que unam esforços no sentido de minimizar ou idealmente extinguir a parcela de excluídos digitais (re)integrando-os ao contexto sócio-econômico-cultural, favorecendo, assim, não apenas a estes, porém a sociedade como um todo.

Tabela 01:Percentual de Incluídos Digitais- RN.

Fonte: CPS/IBRE/FGV a partir dos microdados

Censo Demográfico de 2000/IBGE.

\begin{tabular}{|c|c|c|c|c|c|}
\hline Ordem & Município & Inclusão & Ordem & Município & Inclusão \\
\hline 1 & Natal & 13.78 & 70 & São Fernando & 0.81 \\
\hline 2 & Parnamirim & 10.16 & 71 & Vera Cruz & 0.81 \\
\hline 3 & Mossoró & 5.58 & 72 & Monte Alegre & 0.8 \\
\hline 4 & Caicó & 4.72 & 73 & Rafael Godeiro & 0.79 \\
\hline 5 & Pau dos Ferros & 4.71 & 74 & Coronel Ezequiel & 0.77 \\
\hline 6 & Viçosa & 4.5 & 75 & Encanto & 0.77 \\
\hline 7 & Açu & 3.8 & 76 & São Pedro & 0.77 \\
\hline 8 & Taboleiro Grande & 3.73 & 77 & Angicos & 0.76 \\
\hline 9 & Ipueira & 3.67 & 78 & Bom Jesus & 0.75 \\
\hline 10 & Areia Branca & 3.6 & 79 & Várzea & 0.75 \\
\hline 11 & Pedra Preta & 3.52 & 80 & $\begin{array}{c}\text { Serra de São } \\
\text { Bento }\end{array}$ & 0.73 \\
\hline 12 & Goianinha & 3.44 & 81 & Pedro Velho & 0.71 \\
\hline 13 & Macau & 3.05 & 82 & Portalegre & 0.71 \\
\hline 14 & Currais Novos & 3.03 & 83 & $\begin{array}{c}\text { Rodolfo } \\
\text { Fernandes }\end{array}$ & 0.71 \\
\hline 15 & Carnaúba dos Dantas & 2.78 & 84 & $\begin{array}{l}\text { São José de } \\
\text { Campestre }\end{array}$ & 0.71 \\
\hline 16 & Parelhas & 2.66 & 85 & Pureza & 0.7 \\
\hline 17 & Coronel & 2.63 & 86 & Ielmo Marinho & 0.68 \\
\hline 18 & $\begin{array}{l}\text { São Francisco do } \\
\text { Oeste }\end{array}$ & 2.57 & 87 & Itaú & 0.68 \\
\hline 19 & Santa Cruz & 2.55 & 88 & Jucurutu & 0.68 \\
\hline 20 & Ceará-Mirim & 2.03 & 89 & Itajá & 0.66 \\
\hline 21 & Parazinho & 1.89 & 90 & Francisco Dantas & 0.65 \\
\hline 22 & Fernando & 1.87 & 91 & Major Sales & 0.61 \\
\hline 23 & $\begin{array}{l}\text { São Gonsalo do } \\
\text { Amarante }\end{array}$ & 1.84 & 92 & Florânia & 0.6 \\
\hline 24 & Felipe Guerra & 1.82 & 93 & Ruy Barbosa & 0.6 \\
\hline 25 & Equador & 1.72 & 94 & Messias Targino & 0.59 \\
\hline 26 & Jardim do Seridó & 1.71 & 95 & Lagoa Nova & 0.58 \\
\hline 27 & Cruzeta & 1.7 & 96 & Baraúna & 0.57 \\
\hline 28 & Alto dos Rodrigues & 1.65 & 97 & Martins & 0.57 \\
\hline 29 & Lucrécia & 1.64 & 98 & $\begin{array}{l}\text { São Paulo do } \\
\text { Potengi }\end{array}$ & 0.57 \\
\hline 30 & Nísia Floresta & 1.63 & 99 & $\begin{array}{l}\text { Jardim de } \\
\text { Piranhas }\end{array}$ & 0.56 \\
\hline 31 & Acari & 1.61 & 100 & Montanhas & 0.55 \\
\hline 32 & Grossos & 1.59 & 101 & Barcelona & 0.53 \\
\hline
\end{tabular}




\begin{tabular}{|c|c|c|c|c|c|}
\hline 33 & João Câmara & 1.59 & 102 & Carnaubais & 0.53 \\
\hline 34 & Almino Afonso & 1.57 & 103 & Arês & 0.52 \\
\hline 35 & Patu & 1.53 & 104 & Galinhos & 0.48 \\
\hline 36 & Paraú & 1.5 & 105 & Alexandria & 0.47 \\
\hline 37 & Água Nova & 1.5 & 106 & São Miguel & 0.47 \\
\hline 38 & Santa Maria & 1.48 & 107 & Poço Branco & 0.46 \\
\hline 39 & Apodi & 1.45 & 108 & Frutuoso Gomes & 0.45 \\
\hline 40 & Macaíba & 1.44 & 109 & Touros & 0.43 \\
\hline 41 & Nova & 1.41 & 110 & Riachuelo & 0.42 \\
\hline 42 & Serrinha dos Pintos & 1.41 & 111 & São Tomé & 0.42 \\
\hline 43 & Extremoz & 1.37 & 112 & Upanema & 0.42 \\
\hline 44 & Tibau do Sul & 1.36 & 113 & Brejinho & 0.41 \\
\hline 45 & Serra Negra do Norte & 1.35 & 114 & Lagoa Salgada & 0.4 \\
\hline 46 & Augusto Severo & 1.32 & 115 & $\begin{array}{l}\text { São José do } \\
\text { Sabugi }\end{array}$ & 0.4 \\
\hline 47 & Jaçanã & 1.31 & 116 & Ipanguaçu & 0.36 \\
\hline 48 & São Bento do Norte & 1.3 & 117 & Luís Gomes & 0.36 \\
\hline 49 & Severiano Melo & 1.28 & 118 & Rio do Fogo & 0.36 \\
\hline 50 & Guamaré & 1.27 & 119 & Januário Cicco & 0.33 \\
\hline 51 & Bento Fernandes & 1.25 & 120 & Taipu & 0.31 \\
\hline 52 & $\begin{array}{c}\text { Governador Dix-Sept } \\
\text { Rosado }\end{array}$ & 1.25 & 121 & $\begin{array}{l}\text { Presidente } \\
\text { Juscelino }\end{array}$ & 0.29 \\
\hline 53 & Caraúbas & 1.23 & 122 & Janduís & 0.28 \\
\hline 54 & Santo Antônio & 1.14 & 123 & Pilões & 0.28 \\
\hline 55 & Canguaretama & 1.12 & 124 & Lagoa de Pedras & 0.27 \\
\hline 56 & Umarizal & 1.1 & 125 & Tibau & 0.27 \\
\hline 57 & Antônio Martins & 1 & 126 & Tenente Ananias & 0.24 \\
\hline 58 & Marcelino Vieira & 1 & 127 & Lajes & 0.23 \\
\hline 59 & São José de Mipibu & 1 & 128 & Rafael Fernandes & 0.22 \\
\hline 60 & Baía Formosa & 0.98 & 129 & Tangará & 0.21 \\
\hline 61 & Pedro Avelino & 0.94 & 130 & São Rafael & 0.2 \\
\hline 62 & Pendências & 0.93 & 131 & Japi & 0.19 \\
\hline 63 & Cerro Corá & 0.91 & 132 & Serra do Mel & 0.19 \\
\hline 64 & José da Penha & 0.90 & 133 & São Vicente & 0.19 \\
\hline 65 & Caiçara do Norte & 0.88 & 134 & $\begin{array}{c}\text { Jardim de } \\
\text { Angicos }\end{array}$ & 0.17 \\
\hline 66 & Campo Redondo & 0.86 & 135 & Afonson Bezerra & 0.16 \\
\hline 67 & Serrinha & 0.82 & 136 & Jandaíra & 0.15 \\
\hline 68 & São Miguel de Touros & 0.82 & 137 & Ouro Branco & 0.14 \\
\hline \multirow[t]{2}{*}{69} & Passa e Fica & 0.81 & 138 & Maxaranguape & 0.12 \\
\hline & & & 139 & Santana do Matos & 0.07 \\
\hline
\end{tabular}




\section{REFERÊNCIAS}

HENRIQUE MOURA, D.Sociedade, educação tecnologia e o uso das TIC nos processos educativos.

HENRIQUE MOURA, D. La organición educativa y la investigación evaluativa. Parte do capítulo III da tese de doutorado La Autoevaluación como instrumento de Mejora de Calidad: un Estudio de Caso(el Centro Federal de Educação Tecnológica /CEFET/RN/Brasil). Madri: Tese de doutorado defendida junto ao Departamento de Didática e Organização Escolar da Universidade Complutense de Madri, 2003Organización Escolar da UniversidadeComplutense de Madri, 2003. Pág 35 a 67.

FALCÃO, Reginaldo Araújo. Uso de Ambientes Virtuais através da Internet no

Ensino a Distância: Aplicação no CEFET/RN. Dissertação de Mestrado em

Engenharia de Produção com Ênfase em Mídia e Conhecimento - Universidade Federal de Santa Catarina, fevereiro 2001.

Frigotto, G. A produtividade da escola improdutiva: um reexame das relações entre educação e estrutura econômico-social capitalista. IN: A produtividade da escola improdutiva. 5a Ed. .São Paulo: Cortez, 1999, pág 133 a 212.

BURBULES, N. C. e TORRES, C. A. (orgs.) Globalização e educação: uma introdução

Globalização e educação: perspectivas críticas. $1^{\text {a }}$ Ed.. Porto Alegre: Artmed, 2004 pág. 11 a 26.

Andrade, A. A. M. Globalização x educação. $1^{\text {a }}$ Ed.. IN: Globalização \& desigualdade. Natal: A. S. editores, 2002, pág 177 a 186.

CAMPOS, B. T. Escolas municipais terão acesso à Internet: depoimento [4 de julho, 2004]. Natal: Pirangi Notícias. Entrevista concedida a Gladson Morais.

CAMPOS, B. T. Escolas municipais terão acesso à Internet. Pirangi Notícias, Natal, p. 6, 4 jul. 2004.

SMITH, T. E.; SCHOLZ, J. Isto é Grandes temas : Inteligência artificial. [filme-vídeo]. Produção de Timothy E. Smith, direção de Julie Scholz. São Francisco - CA -EUA. Instituto de tecnologia de Massechuts, 1995. 1 casssete VHS/NTSC, 39 min. color, som.

\section{INTERNET}

FUNDAÇÃO GETÚLIO VARGAS -CENTRO DE POLÍTICAS SOCIAIS. Mapa da exclusão digital:Sumário executivo. Disponível em

<http://www2.fgv.br/ibre/cps/mapa_exclusao/SUMARIO/sumario\%20interativo.htm

$>$ Acesso em: 30 de jul. 2004

UFMG. Curso de linguagem C. Disponível em $<\underline{\text { http://www.ead.eee.ufmg.br/cursos/C }>}$

Acesso em: 30 de jul. 2004

UFMG. Curso de linguagem C:Informações gerais. Disponível em

<http://www.ead.eee.ufmg.br/cursos/C/info.htm> Acesso em: 30 de jul. 2004 